\title{
Bacterial Community Structure in Anaerobic Digesters of a Full Scale Municipal Wastewater Treatment Plant - Case Study of Dubai, United Arab Emirates
}

\section{Munawwar A. Khan*1, Noorun N. Ashar ${ }^{2}$, Arpitha G. Ganesh ${ }^{3}$, Naushad Rais ${ }^{4}$ Sultan M. Faheem ${ }^{5}$, Shams T. Khan ${ }^{6}$}

${ }^{1}$ Department of Life and Environmental Sciences, College of Natural and Health Sciences, Zayed University, P.O. Box: 19282, Dubai, United Arab Emirates e-mail: Munawwar.Khan@zu.ac.ae

${ }^{2}$ School of Life Sciences, Manipal University, Dubai International Academic City, P.O. Box: 345050,

Dubai, United Arab Emirates e-mail: naushad@manipaldubai.com

${ }^{3}$ Department of Life and Environmental Sciences, College of Natural and Health Sciences, Zayed University, P.O. Box: 19282, Dubai, United Arab Emirates e-mail: arpitha.hebbar.g@gmail.com

${ }^{4}$ School of Life Sciences, Manipal University, Dubai International Academic City, P.O. Box: 345050,

Dubai, United Arab Emirates e-mail: naushad@manipaldubai.com

${ }^{5}$ School of Life Sciences, Manipal University, Dubai International Academic City, P.O. Box: 345050, Dubai, United Arab Emirates e-mail: smfaheem@manipaldubai.com

${ }^{6}$ Department of Agricultural Microbiology, Aligarh Muslim University, Aligarh,

Uttar Pradesh 2002002, India

e-mail: shamsalig75@gmail.com

Cite as: Khan, M. A., Ashar, N. N., Ganesh, A. G., Rais, N., Faheem, S. M., Khan, S. T., Bacterial Community Structure in Anaerobic Digesters of a Full Scale Municipal Wastewater Treatment Plant - Case Study of Dubai, United Arab Emirates, J. sustain. dev. energy water environ. syst., 7(3), pp 385-398, 2019, DOI: https://doi.org/10.13044/j.sdewes.d6.0222

\section{ABSTRACT}

A highly complex microbial community involved in anaerobic sludge digesters plays vital roles in sludge treatment. The data on microbial ecology is important to accomplish efficient operation of the anaerobic digesters. This study is aimed at monitoring the bacterial community of three full-scale anaerobic digesters of a full-scale municipal wastewater treatment Plant in Dubai, United Arab Emirates. Fluorescent in-situ hybridization technique was applied to identify the bacterial groups and quantitative polymerase chain reaction to compare the richness of bacterial and archaeal domain. Results of the fluorescent in-situ hybridization technique analysis showed that the phylum Proteobacteria was most abundant followed by cytophage-Flavobacterium group of Bacteroides, Firmicutes and Actinobacteria. Among proteobacterial subclass Delta- and Alpha- were dominating than Gamma- and Beta-proteobacteria. The genus Desulfobacter and Desulfobacterium were the dominant groups hybridizing 70-76\% of total 4', 6'-diamidino - 2 phenylindole stained cells. The quantitative polymerase chain reaction results showed that Bacterial domain was dominating in all three digesters compared to the archaeal domain.

\footnotetext{
${ }^{*}$ Corresponding author
} 


\section{KEYWORDS}

Anaerobic digester, Bacterial community, Fluorescence in situ hybridization, Oligonucleotide probes, Quantitative polymerase chain reaction.

\section{INTRODUCTION}

Gaining knowledge on the association between microbial community and wastewater treatment efficiency is critical for the effective operation of wastewater treatment plants. Several studies had led to quantification and classification of important microorganisms capable of the treatment of wastewater biosolids over the past few years [1-3]. Anaerobic digestion is a widely used method for wastewater biosolids treatment, which reduces the impact of the organic pollutants on the environment. Anaerobic degradation of this biological waste is carried out by various bacterial species present in the digesters including hydrolytic, acid forming, acetogenic, and methanogenic archaea that produce Carbon dioxide $\left(\mathrm{CO}_{2}\right)$ and Methane $\left(\mathrm{CH}_{4}\right)$ as by products [4]. Each step is driven by a group of microorganisms. To confirm a steady process, it is vital to uphold equilibrium in reaction rate among the four steps [5]. The first step is hydrolysis in which the complex substance is hydrolyzed into monomers and dimers such as glucose and amino acids. Two phyla that consist mostly of the hydrolytic bacteria are Firmicutes and Bacteroidetes mainly in the genera Streptococcus, Acetivibrio, Enterobacterium and Clostridium [6]. The second stage is acidogenesis in which acid forming bacteria ferment the hydrolytic products into volatile fatty acids, acetate and hydrogen. The phyla that contain many known species of acidogens are Firmicutes, Bacteroidetes, Chloroflexiand Proteobacteria [7]. Lactobacillus in the phylum Firmicutes, Anaerolinaceae in the phylum Chloroflexi, Bifidobacterium in the phylum Actinobacteria and a few thermophilic bacteria in the phylum Thermotogaecontain non-hydrolytic acidogens [8]. In the third stage, some of the acid phase intermediate products that cannot be directly used by methanogens are converted into acetate and hydrogen, which can then be used by methanogens. The hydrogen released during acetogenesis exhibits toxic effects on acetogens hence this process takes place in a symbiotic relationship between acetogens and autotrophic methanogens [9]. The acetogens belong to the genera Syntrophomonas and Syntrophobacter (in the phylum Firmicutes and Proteobacteria) [10]. The last stage is methanogenesis in which most commonly observed methanogenic genera such as Methanolinea, Methansaeta, and Methanospirillum produce methane using the by-products of previous stages [11].

In the anaerobic digesters along with methanogens and acetogens, sulfate-reducing bacteria are also found. In the presence of sulphate they multiply which often requires hydrogen and acetate, which are the substrates utilized by methanogens [12]. A competition occurs between the two bacterial groups for hydrogen, as both the groups need hydrogen. In such situation sulfate reducing bacteria reap hydrogen and acetate more effortlessly than methanogens [12]. The hydrogen sulphide produced by sulfate reducing bacteria on the degradation of sulphate exhibits inhibitory effects at low levels on methanogens and acetogens than on acidogens. Synergistic relationships exist between acetogens and methanogens for methane production. As a result of digestion, microorganisms metabolize fatty acids and alcohols during which Syntrophic bacteria produce Adenosine Triphosphate (ATP) [13]. Methanogens then utilize these compounds after being converted into acetate and hydrogen. Syntrophomonas genus produces acetate, hydrogen and $\mathrm{CO}_{2}$ upon oxidation of organic acids, which are used by methanogens [9]. This syntrophic association of methanogens and acetogens play a role in the oxidation of propionate, which is likewise a vital phase of methanogenesis process [4]. Another kind of symbiosis is seen between methanogens and bacterial group, which is mostly sulfate reducing bacteria belonging to $\delta$ sub division of Proteobacteria [14]. 
To enumerate the presence and relative richness of microbial populations in the sample Fluorescence In Situ Hybridization (FISH) technique is commonly used. FISH is a taxonomic method, which is used for identifying the presence of various phylogenetic groups in an environmental sample. It also provides the direction visualization of the microbial cells. Therefore, hybridization with rRNA-targeted probes has dramatically increased the efficiency of characterization of uncultured microorganisms in a given sample [15].

One of the major wastewater treatment plants in Dubai, UAE is the Jebel Ali Wastewater Treatment Plant (JAWWTP) whose efficient operation and maintenance is indispensable for the city of Dubai. A detailed understanding of microbial community structure and functions is vital for the sustainable management of biosolids generated at various stages of wastewater treatment processes. This study is aimed at monitoring the bacterial community in the anaerobic digesters of a full-scale municipal wastewater treatment Plant in Dubai over a period of five months. FISH technique was employed on the samples with previously published probes for identifying the bacterial community structure of the anaerobic digesters. Series of probes targeting phyla, groups and subgroups were used. For comparing the abundance among bacteria and archaea domain real-time quantitative Polymerase Chain Reaction (qPCR) was used.

\section{MATERIALS AND METHODS}

A total of 15 sludge samples were collected from three full-scale anaerobic digesters $(1,3$, and 5) from JAWWTP, UAE on a monthly basis. Out of three, digester no. 3 is the oldest and digester no. 5 is the newest. All three anaerobic digesters were operating at a mesophilic temperature $32-37^{\circ} \mathrm{C}$. The capacity of each digester was $7,433 \mathrm{~m}^{3}$. All three digesters were fed with $60 \%$ of raw sludge and the $40 \%$ of activated sludge. The operating physiochemical parameters of anaerobic digesters at the time of sample collection are described in Table 1.

The samples were collected from the anaerobic digesters into autoclaved plastic bottles. The bottles were placed in an icebox and brought to the laboratory within an hour. The collected samples were stored at $4{ }^{\circ} \mathrm{C}$ until DNA extraction and fixation of biomass for FISH analysis. The samples were fixed with paraformaldehyde within 24 hours. After fixation the samples were stored at $-20{ }^{\circ} \mathrm{C}$.

Table 1. Anaerobic sludge digester operational parameters

\begin{tabular}{|c|c|c|c|}
\hline Parameters & Digester-1 & Digester-3 & Digester-5 \\
\hline Digester capacity $\left[\mathrm{m}^{3}\right]$ & 7,433 & 7,433 & 7,433 \\
\hline $\mathrm{pH}^{*}$ & $7.13-7.5$ & $7.27-7.55$ & 7.36 \\
\hline Temperature $\left[{ }^{\circ} \mathrm{C}\right]$ & 34 & 34 & 34 \\
\hline Digester feeding per day $\left[\mathrm{m}^{3}\right]$ & 2,248 & 2,148 & 2,552 \\
\hline Solid retention time (days) & 16 & 16 & 14 \\
\hline Up flow velocity $\left[\mathrm{m}^{3} / \mathrm{hr}\right]$ & 120 & 120 & 120 \\
\hline Hydraulic Retention Time (HRT) (days) & 3.3 & 3 & 2.91 \\
\hline Organic loading rate $\left[\mathrm{kg}\right.$ oDS $\left./ \mathrm{m}^{3} \mathrm{~d}\right]$ & 6.84 & 5.84 & 6.61 \\
\hline Dry solid* $[\%]$ & $2.91-3.34$ & $2.56-5.74$ & $2.79-3.54$ \\
\hline Volatile solids* $[\%]$ & $70.27-70.95$ & $43.75-70.15$ & 54.54-67.49 \\
\hline Volatile fatty acid* & $165-195$ & $168-205$ & $145.5-195$ \\
\hline Alkalinity $^{*}$ & $3,014-3,451$ & $2,992-3,512$ & $2,893-3,190$ \\
\hline Dissolved sulfide* $[\mathrm{mg} / \mathrm{L}]$ & $37.2-38$ & $32.4-37.2$ & $26.4-27.6$ \\
\hline
\end{tabular}

Minimum to maximum range observed over the sampling period

The DNA is extracted from the samples obtained from the anaerobic sludge digesters within 24 to 48 hours. Total community DNA was extracted from the samples using the PowerSoil DNA Isolation Kit (MO BIO Labs. Inc., Solana Beach, CA) according to the 
manufacturer's guidelines. The qPCR was performed to relatively quantify and compare the abundance of bacteria with archaea using comparative Cycle Threshold (CT) method $(\Delta \Delta \mathrm{CT})$. The qPCR amplification was performed in $20 \mu \mathrm{l}$ reactions. Each reaction contained $1 \mu \mathrm{l}$ of $20 \times$ reaction mixture $(5 \mu \mathrm{l}$ of $10 \mu \mathrm{M}$ forward primer, $5 \mu \mathrm{l}$ of $10 \mu \mathrm{M}$ reverse primer, $5 \mu \mathrm{l}$ of $5 \mu \mathrm{M}$ probe and $85 \mu \mathrm{l}$ of PCR grade water), $10 \mu \mathrm{l}$ of the TaqMan master mix, $1 \mu$ of DNA sample and $8 \mu$ of PCR grade water. Reactions were performed in duplicates with one control. The reactions were run on an Applied BiosystemsStepOnePlus $^{\mathrm{TM}}$ Real-Time PCR System. The following PCR program was used for all samples: An initial denaturation at $95{ }^{\circ} \mathrm{C}$ for 10 minutes followed by 40 cycles (denaturation at $95{ }^{\circ} \mathrm{C}$ for 15 seconds and annealing/extension at $60{ }^{\circ} \mathrm{C}$ for 1 minute). The details of respective primer and probe are given in Table 2.

Table 2. Characteristics of the probe and primer

\begin{tabular}{|c|c|c|c|c|}
\hline Primer & Target & Function & Sequence & Reference \\
\hline \multirow{3}{*}{ ARC } & \multirow{3}{*}{ Archaea domain } & F primer & ATTAG ATACC CSBGT AGTCC & \multirow{3}{*}{ [16] } \\
\hline & & Taqman probe & AGGAA TTGGC GGGGG AGCAC & \\
\hline & & $\mathrm{R}$ primer & GCCAT GCACC WCCTC T & \\
\hline \multirow{3}{*}{ BAC } & \multirow{3}{*}{ Bacterial domain } & F primer & ACTCC TACGG GAGGC AG & \multirow{3}{*}{ [16] } \\
\hline & & Taqman probe & TGCCA GCAGC CGCGG TAATA C & \\
\hline & & $\mathrm{R}$ primer & GACTA CCAGG GTATC TAATC C & \\
\hline
\end{tabular}

The composition of the bacterial communities in this study was determined by using various oligonucleotide probes [17]. Slides were washed with acid alcohol, dried and coated with poly-L-lysin by placing them in the Coplin jars containing the poly-L-lysine solution. The slides were then dried. Approximately $1 \mathrm{ml}$ of the sample obtained from the sludge digesters were fixed in formaldehyde. An aliquot of 1-3 $\mu 1$ of formaldehyde fixed-cell samples were applied to the wells on poly-L-lysin-coated slides allowed to air dry and dehydrated in a series of ethanol solution (50\%, 80\% and 96\%, 3 minutes each). The slides were air dried, and in each well $10 \mu \mathrm{l}$ of hybridization mixture (containing $9 \mu 1$ of hybridization solution and $1 \mu$ l of oligonucleotide probe) was added (Table 3). The slides were incubated at $37{ }^{\circ} \mathrm{C}$ for 4 hours in a moisture chamber for hybridization. Slides were rinsed with $1 \mathrm{ml}$ of the pre-warmed $\left(48{ }^{\circ} \mathrm{C}\right.$ for 30 minutes) washing solution. The slides were washed by placing the slides in chambers containing $30 \mathrm{ml}$ of respective washing solution. The slides were then air dried and visualized under Fluorescent Microscope, OlympusBX-51 Series connected to a digital camera DP-72.

Table 3. Sequence of oligonucleotide probes used in this study

\begin{tabular}{|c|c|c|c|c|c|}
\hline Probe name & Sequence $\left(5^{\prime}-3^{\prime}\right)$ & Target & FA [\%] & Rank & Reference \\
\hline LGC354a & TGGAAGATTCCCTACTGC & \multirow{3}{*}{$\begin{array}{c}\text { Firmicutes } \\
\text { (gram positive with low } \mathrm{G}+\mathrm{C} \% \text { ) }\end{array}$} & \multirow{3}{*}{35} & \multirow{3}{*}{ Phylum } & \multirow{3}{*}{ [18] } \\
\hline LGC354b & CGGAAGATTCCCTACTGC & & & & \\
\hline LGC354c & CCGAAGATTCCCTACTGC & & & & \\
\hline Gam42a & GCCTTCCCACATCGTTT & $V$-proteobacteria & 35 & Class & [19] \\
\hline Bet42a & GCCTTCCCACTTCGTTT & $\beta$-proteobacteria & 35 & Class & [19] \\
\hline SRB281 & TCAGACCAGCTAACCATC & Various $\delta$-proteobacteria & 10 & Class & [20] \\
\hline ALF1b & CGTTCGYTCTGAGCCAG & $\alpha$-proteobacteria & 20 & Class & [19] \\
\hline HGC69a & TATAGTTACCACCGCCGT & $\begin{array}{c}\text { Actinobacteria } \\
\text { (high G + C grampositive bacteria) }\end{array}$ & 25 & Phylum & [21] \\
\hline 129 & CAGGCTTGAAGGCAGATT & Desulphobacter & 15 & Genus & [22] \\
\hline 221 & TGCGCGGACTCATCTTCAAA & Desulphobacterium & 35 & Genus & [22] \\
\hline CF319a & TGGTCCGTGTCTCAGTAC & Cytophagagroup of the Bacteroides & 35 & Genus & [23] \\
\hline EUB338I & GCTGCCTCCCGTAGGAGT & \multirow{3}{*}{ Bacterial domain } & \multirow{3}{*}{25 and 35} & \multirow{3}{*}{ Domain } & \multirow{3}{*}[24]{} \\
\hline EUB338II & GCAGCCACCCGTAGGTGT & & & & \\
\hline EUB338III & GCTGCCACCCGTAGGTGT & & & & \\
\hline
\end{tabular}




\section{RESULTS AND DISCUSSION}

The JAWWTP consists of five full-scale anaerobic digesters designated as AD1-5. For this study sludge samples were obtained from AD 1, 3 and 5. The three digesters in order of age, newest to oldest, is $\mathrm{AD} 5, \mathrm{AD} 1$ and $\mathrm{AD} 3$. The relative abundance of bacterial groups was examined by performing FISH with bacteria-specific probes (EUB338 mix) and 8 different bacterial group-specific probes (Table 2).

Under optimal hybridization conditions, specific groups of bacteria were observed and detected using the corresponding probes. Figure 1 shows representative epifluorescence micrographs of the targeted bacterial cells in the anaerobic digester sludge samples. Most of the bacterial community got hybridized with EUBmix probe (targeted at eubacterial domain). The percentage of cells hybridized by the probe EUBmix ranged between 54-89\% of total 4', 6'-diamidino-2 phenylindole (DAPI) stained cells, in all the three digesters throughout the study period. EUBmix probe targeted cells of various morphologies like cocci, rods and filaments. A few diplococci and short rods could be observed (Figure 1).

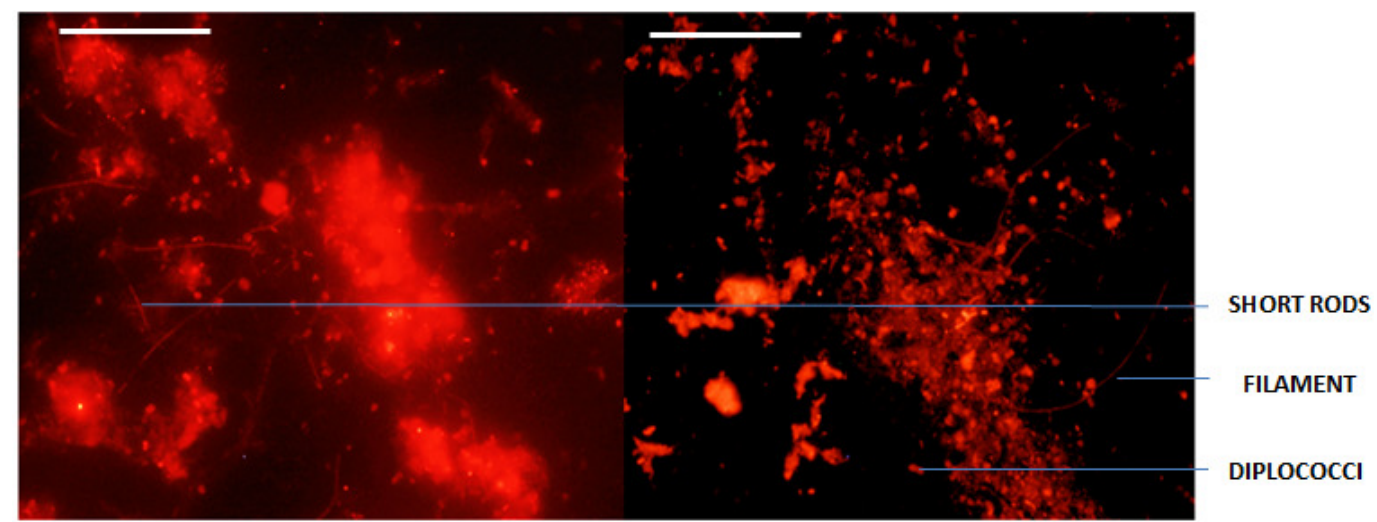

Figure 1. Epifluorescence micrograph showing in situ hybridization with probe EUBmix - Cy3, scale $=10 \mu \mathrm{m}$ and applies to all photomicrographs (original magnification: $1,000 \times$ )

Results from the FISH analysis for each digester throughout the sampling months are shown in Figure 2.

The samples were investigated for the population of different phyla. It was observed that Actinobacteria (24.27-25.24\% of the total bacteria) constituted the lowest population in digester 3 and 1, when compared to Firmicutes (30.57-36.68\%) and CytophagaFlavobacterium (CF) group of Bacteroidetes (37.19-31.32\%). Conversely, Actinobacteria (32.88\%) was higher than Firmicutes (30.2\%) in digester 5. CF group was dominating in digester 5 and 3 compared to Firmicutes and Actinobacteria. Among the probes targeted, the proteobacterial subclasses Delta- and Alphaproteobacteria (between $38.5 \%$ and $44.4 \%$, respectively) was dominating than Gamma- and Betaproteobacteria (between $24.8 \%$ and $35 \%$ respectively) in all digesters. Delta appeared to occur more than Alpha in all digesters whereas Gamma was dominating than Beta in digester 3 and vice versa in digester 5 . They were equally dominating in digester 1 .

The members of the genus Desulfobacter (72.15\%) and Desulfobacterium (73.3\%) of class Deltaproteobacteria occurred in high numbers consistently not only in digester 1 but also in other two digesters throughout the study period, except in three samples (Figure 2). The prior presence of a large amount of Desulfovibrio and Desulfobacterium group and a smaller proportion of other SRB could be attributed to the immediate reduction of sulphate [25]. Results obtained in this study were different from the study of Raskin et al. [25] and Griffin et al. [26], wherein low levels of Desulfobacter and Desulfobacterium were observed in the anaerobic digesters. Griffin et al. [26] reported 
that the low levels of feed sulphate were responsible for low population of SRB, making the survival of the SRB's difficult consequently resulting in high methane production.

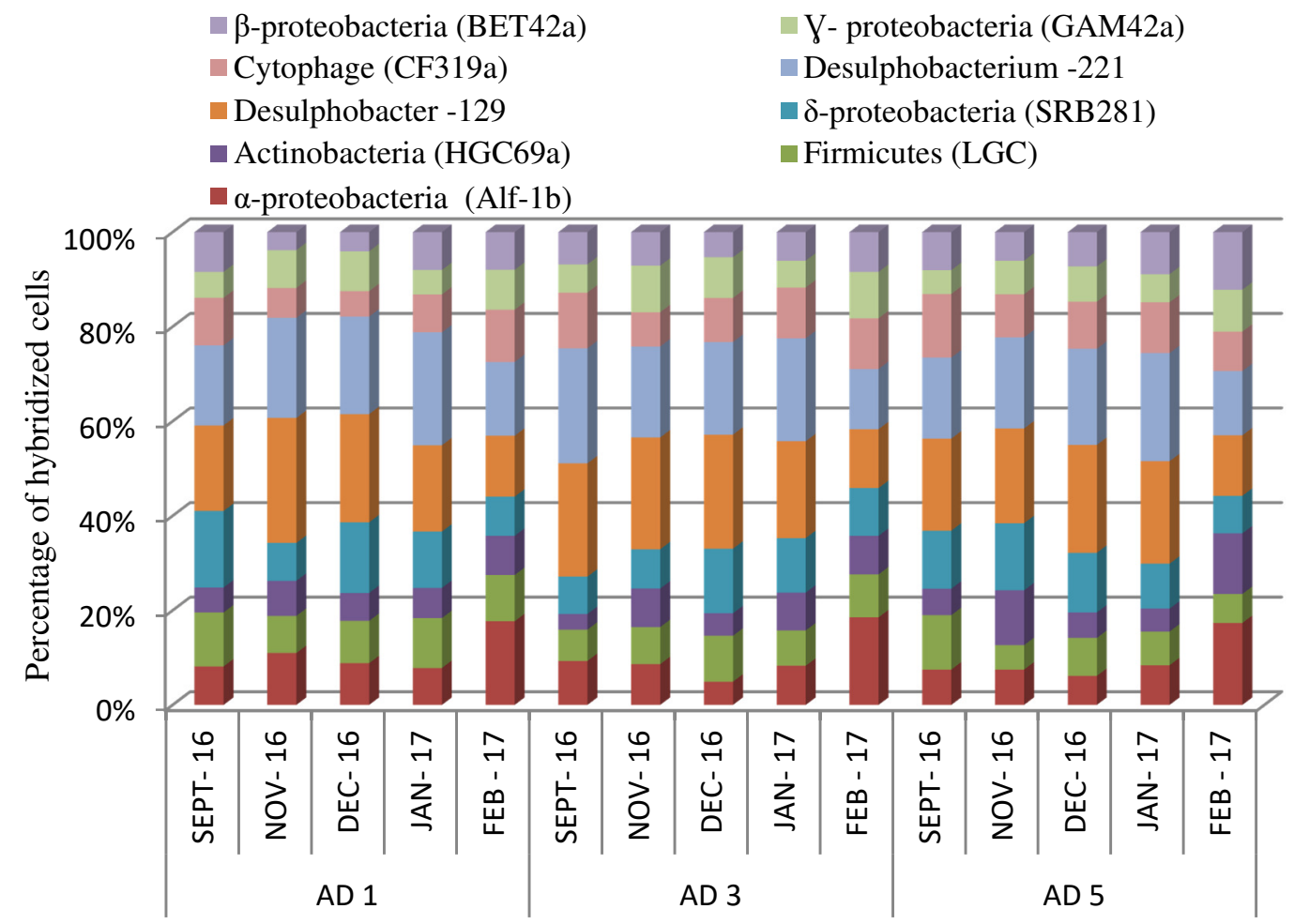

Anaerobic digesters during sampling month

Figure 2. FISH targeted cells for each of the anaerobic digesters for different sampling period

Since the SRB can compete with methanogenic bacteria for hydrogen and acetate, the high concentration of SRB might reduce the overall methane yield. Some previous studies have reported SRB can grow in sulfate-restricted environments [27] due to their aptitude to syntrophically grow with methanogens in the absence of sulphate [28]. A study conducted by Raskin et al. [29] reported less fraction of Desulfobacter and a comparatively high fraction of Desulfobacterium in methanogenic reactors. But the average of cells hybridized by Desulfobacterium was less compared to this study (Figure 3).

At the phylum level, the most abundant bacterial groups were found to be Proteobacteria followed by CFB group of Bacteroidetes, Firmicutes, and Actinobacteria. Abundance levels though slightly different but almost similar levels of population were observed in previous study [30]. However, different results were obtained in the study of Zhao et al. [31], who observed that Firmicutes was predominant phyla, representing 92.3\% of overall sequences in anaerobic sludge. Sundberg et al. [2] reported Firmicutes as dominant phyla and Proteobacteria, as less compared to Bacteroidetes and Actinobacteria. Another study conducted by Nelson et al. [3] utilizing meta-analysis of accessible sequences in public databases from anaerobic digesters showed Proteobacteria and Chlorofexi as the dominant groups which are to some extent consistent with the results of this study, where Proteobacteria was dominating in all three digesters throughout the study period.

Many groups of bacteria, like Alpha-, Beta-, Gamma-, and Delta-proteobacteria are well-known glucose, butyrate, propionate, and acetate-utilizing microbial communities in the sludge. And hence, Proteobacteria are the important microbes in the process of anaerobic digestion [32]. Among Proteobacteria, Delta- and Alphaproteobacteria were 
predominant class that is in concurrence with a previous study [2], where Deltaproteobacteria constituted up to $7 \%$ of the total bacteria while other groups of Proteobacteria only contribute less than $1 \%$ of the total population.

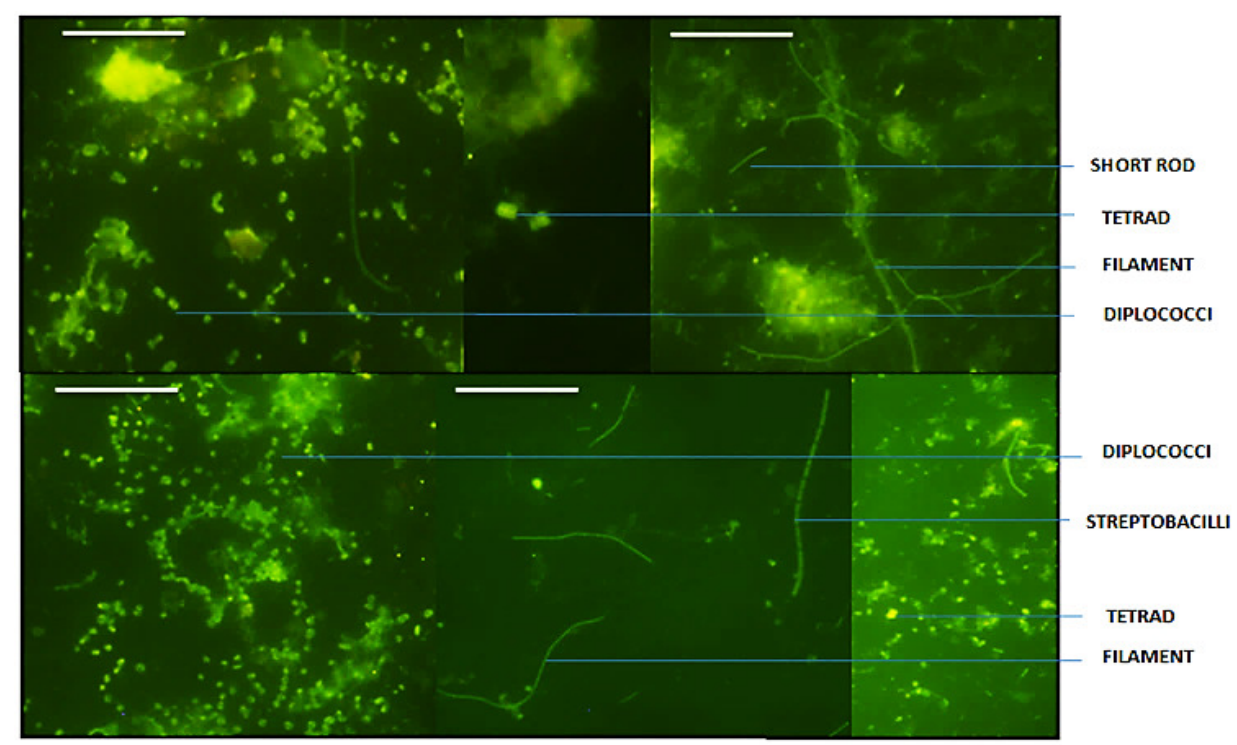

Figure 3. Epifluorescence micrograph showing in situ hybridization with probe; 129 - FITC (a) and $221-$ FITC $(\mathrm{b})($ scale bar $=10 \mu \mathrm{m})$

The probe SRB281 targeted rods, which were dominating, and these rods occurred in diplobacillus and streptobacillus arrangement (Figure 4) but single cell rods were dominating, probably Syntrophobacter species. A few of the cocci targeted by the probe SRB281 was in tetrad arrangement. Deltaproteobacteria comprises of sulphate reducers and syntrophic bacteria (Syntrophobacter) that metabolise propionate, a main intermediate in the anaerobic digestion process, in the relationship with hydrogenotrophs [33].

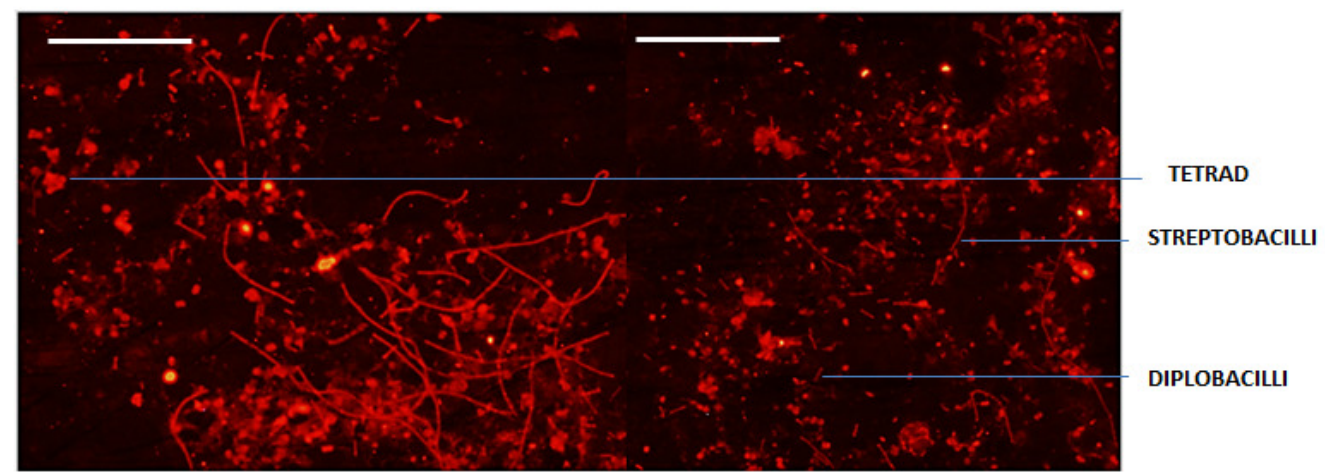

Figure 4. Epifluorescence micrograph showing in situ hybridization with probe SRB281 - Cy3, (scale bar $=10 \mu \mathrm{m})$

Significant population of cocci arranged in tetrads were reported by Seviour [34], while fewer single cell rods as identified by the probe Alf $1 \mathrm{~b}$ probably belonging to alpha-subclass of Proteobacteria were also observed [35] (Figure 5a). In the samples targeted by Gam42a several cocci and comparatively less short rods probably Enterobacterium and filaments were seen as reported in a pervious study [35]. Very few diplococcus and tetrad arrangements of cocci were observed (Figure 5b). The probe Bet42a identified filaments, rods and cocci. The rods were arranged in chains (Streptobacilli) and few cocci were arranged as diplococcus (Figure 5c). 


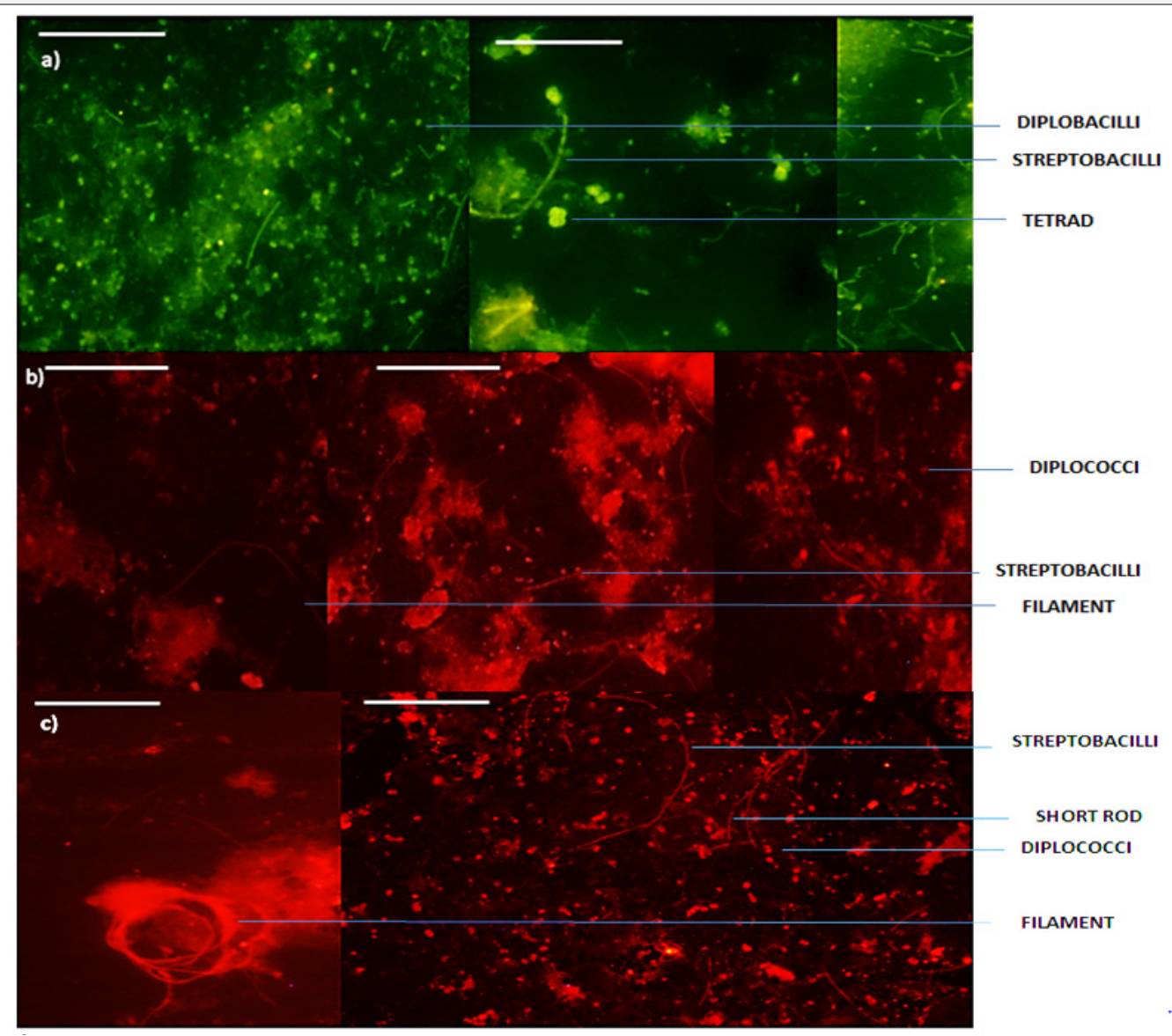

Figure 5. Epifluorescence micrograph showing in situ hybridization with probe; Alf-1b - FITC (a); Gam42a-Cy3 (b) and Beta42a - Cy3 (c) (scale bar $=10 \mu \mathrm{m})$

The second most dominant phyla were Cytophaga-firmicutes group of Bacteroidetes in the anaerobic digesters. The Bacteroidetes comprises of fermentative bacteria, which is assumed to have a critical role in fermenting the organic compounds and acids into $\mathrm{CO}_{2}$ and hydrogen $\left(\mathrm{H}_{2}\right)$ [36]. The probe CF319a targeted cocci, short and chains of rods and few filaments (Figure 6), similar morphology has been reported by in a previous study [36].

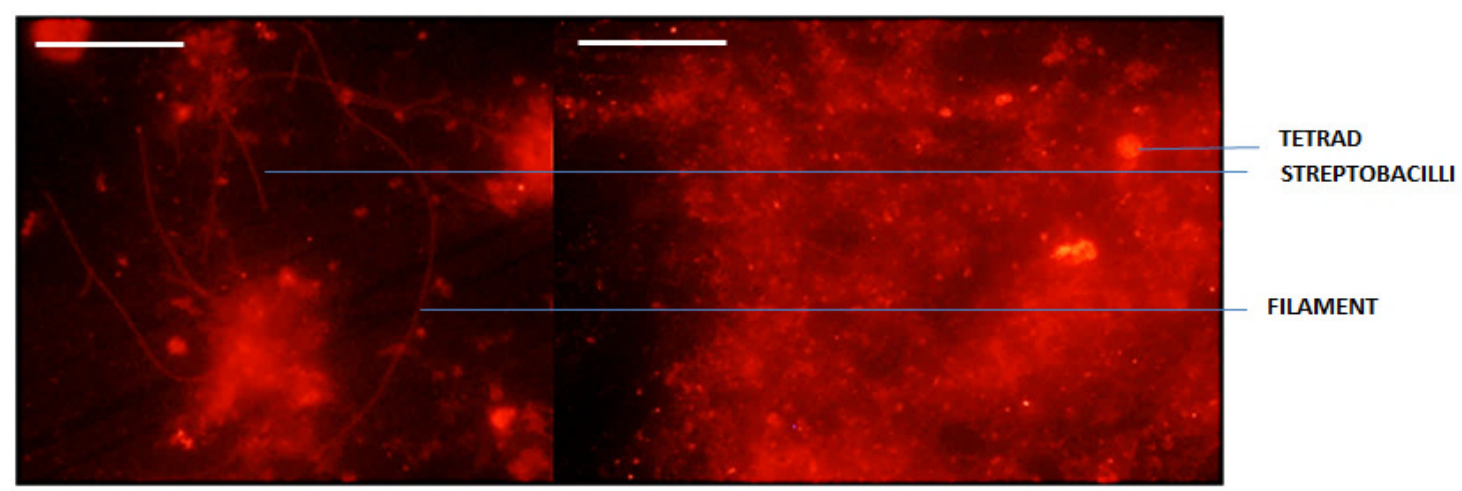

Figure 6. Epifluorescence micrograph showing in situ hybridization with probe CF319a $($ scale bar $=10 \mu \mathrm{m})$

Most of the members belonging to the Firmicutes phylum are syntrophic bacteria that can break down various volatile fatty acids, acetate, valerate, butyrate, isobutyrate and propionate. They are often detected in anaerobic digesters [37]. 
Syntrophomonadaceae group, which belongs to Firmicutes, utilises butyrate for the production of acetate during digestion [38]. In this study, the members of phylum Firmicutes were not targeted. LGC mix probe targeted mostly cocci and rods. The rods were found to be in both single celled and in chains (Streptobacilli) (Figure 7). The single celled curved rods could probably be Syntrophomonadaceae and similar morphology was observed in another study [39]. Quite a few numbers of tetrads were also identified.

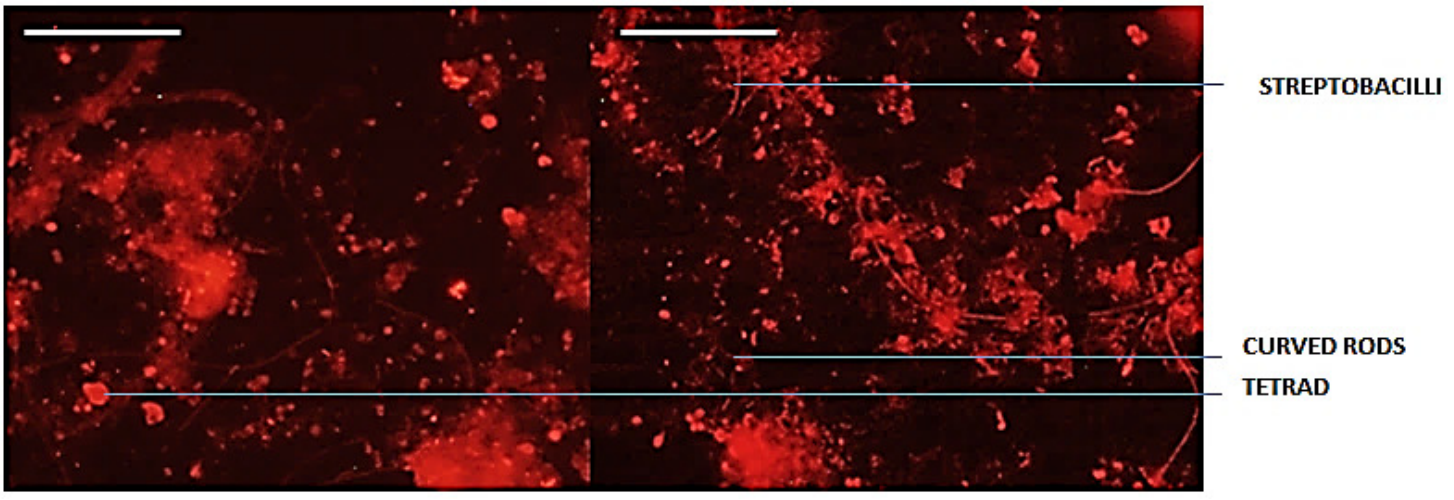

Figure 7. Epifluorescence micrograph showing in situ hybridization with probe LGCmix $($ scale bar $=10 \mu \mathrm{m})$

The phyla Actinobacteria were least dominant in all the digesters, probe HGC69a identified filaments, cocci and few rods. Filaments were slightly dominant than cocci. Streptococci and few Streptobacilli were also observed (Figure 8).

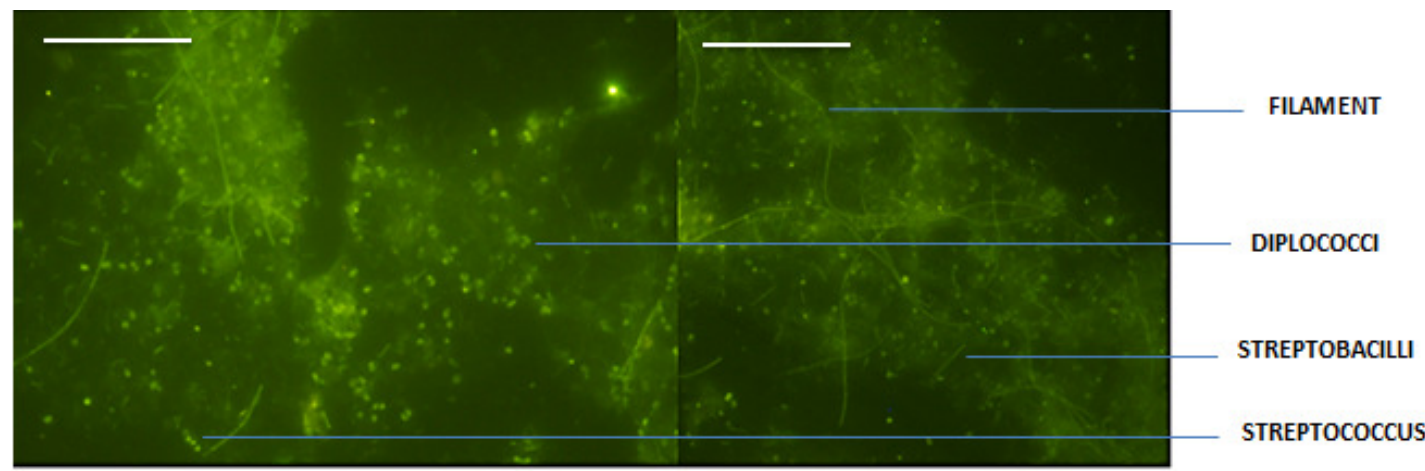

Figure 8. Epifluorescence micrograph showing in situ hybridization with probe HGC69a - FITC (scale bar $=10 \mu \mathrm{m})$

Microbial community structures in full-scale anaerobic reactors have been reported earlier employing metagenomics sequencing approach [1]. This study revealed that Proteobacteria was the most dominant phylum, followed by Cytophaga group of Bacteroidetes, Firmicutes and Actinobacteria, which is consistent with the previous study [2]. Additionally, certain other studies also have reported the bacterial community structure with some disparities in the predominance of population [2]. These variations in the predominant populations may be related to various influent characteristics and operational conditions, which have been reported to strongly influence the microbial community structure [40].

The bacterial structure of each sample was almost consistent in all months barring a few variations in the taxonomic profile. Only during one occasion a considerable change was detected, that was in the month of February, wherein Alphaproteobacteria class was dominating in all digesters compared to other groups (Figure 2) and also the percentage of cells hybridized by the probe Gam42a was highest compared to other sampling months. 
The abundance of bacteria and archaea was tested using qPCR comparative CT method $(\Delta \Delta \mathrm{CT})$. The relative quantification was performed for the sludge samples collected in three consecutive months, namely November, December and January. The low CT value indicates high population of taxa in the target sample, as the CT values are inversely proportional to the concentration of target.

The qPCR results indicated that in all three anaerobic digesters the members of domain bacteria were higher than the domain archaea except in two samples where in the population of both bacteria and archaea were almost equal (Figure 9). The CT value of the bacterial domain across all digesters throughout the sampling period ranged between 14.71 and 20.37, whereas for the archaeal domain it ranges between 18.49 and 22.55.

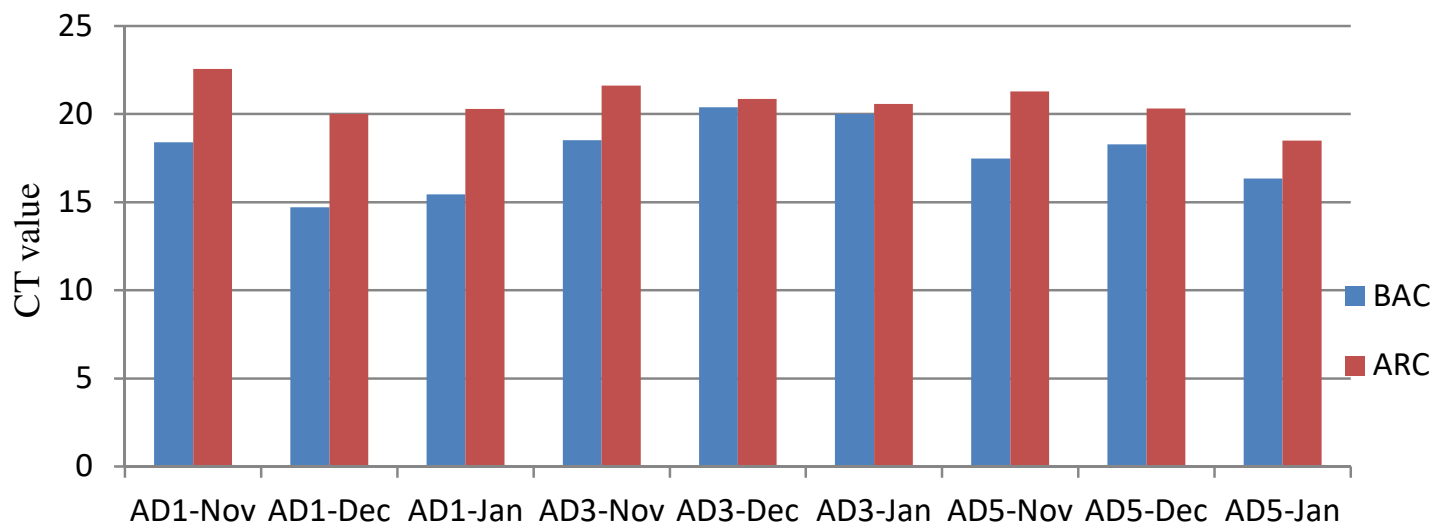

Targeted bacterial community at different time periods

Figure 9. CT values of probe BAC and ARC for each of the digester in different sampling periods

Regueiro et al. [40] studied the microbial community of six full-scale anaerobic digesters with different biomasses and reported the dominance of bacterial population in all biomasses compared to the archaeal community. Also, the high diversity of bacterial community was observed by Regueiro et al. [40] compared to the archaeal community. In this study, FISH analyses also had shown similar results, the number of cells hybridized by EUBmix ranges between 54-89\%, whereas cells hybridized by ARC915 ranges between 27.24-39.19\%. The dominance of the bacterial community compared with archaeal community found in this study is in agreement with prior studies [41, 42].

\section{CONCLUSIONS}

To improve the digestion process in any sludge, the knowledge of microbial community involved and their function is vital. Therefore, this study aimed at understanding the microbial community structure of full-scale anaerobic digesters of a full-scale municipal wastewater treatment plant in the UAE by employing FISH and qPCR, wherein qPCR was mainly used to study the abundance of the bacterial and archaeal domain through comparative $\mathrm{C}_{\mathrm{T}}$ method.

FISH analysis indicated that Proteobacteria was most abundant phylum followed by $\mathrm{CF}$ group of Bacteroidetes, Firmicutes and Actinobacteria in all digesters. In digester 1 and 3, almost similar trends of bacterial community structure was observed at different time periods. The genus Desulfobacter and Desulfobacterium were the most dominant single genera in all the digesters except in three samples, hybridizing with $70-76 \%$ of cells against total DAPI stained cells. These are sulfate reducing bacteria, which are usually found in anaerobic digesters along with acetate forming bacteria, and methane-forming bacteria. The second most dominant were Deltaproteobacteria targeted by the probe SRB281 and Alphaproteobacteria targeted by Alf1b. 
Deltaproteobacteria comprises of sulphate reducers and syntrophic bacteria. The probe SRB281 identified more rods mostly single-celled which could be probably genus Syntrophobacter. The third most dominant group of the bacteria was CF group of Bacteroidetes. The Bacteroidetes consists of fermentative bacteria, which are capable of hydrolysing and fermenting the organic substances and acids into $\mathrm{CO}_{2}$ and $\mathrm{H}_{2}$.

The methane production can be achieved through a step wise process where each step is carried out by different microorganisms in a full-scale anaerobic digester.

qPCR results showed that domain bacteria was more dominant than archaea in all digesters throughout the study period except in two samples where they were present in equal amounts. The members of archaea are only responsible for methanogenesis but the members of the bacteria account for other stages, which take over most of the functions. The diverse bacterial community structure is just an example of their role.

This study provides insights into the microbial community structure ofanaerobic digesters of a full-scale municipal wastewater treatment plant in the UAE. Future work could focus on using high-throughput next-generation sequencing methods for in-depth understanding of the microbial community structure. Also, FISH analysis with newly designed probes targeting genus and species level is likely to provide more details on the microbial functional diversity.

\section{ACKNOWLEDGEMENT}

This research was supported by Zayed University Research Cluster Project: Activity code: R16092 awarded to the first author (PI of the cluster research project). We thank engineer Rashed Mohammad Karkain from JAWWTP for providing samples of anaerobic digesters used in this study.

\section{NOMENCLATURE}

\section{Greek letters}

$\Delta \Delta \mathrm{CT}$

\section{Abbreviations}

$\mathrm{AD}$

ATP

$\mathrm{CF}$

CT

DAPI

FA

FISH

JAWWTP

qPCR

VFA

\section{Comparative CT}
Anaerobic Digester
Adenosine Triphosphate
Cytophaga-Flavobacterium
Cycle Threshold
4', 6'-diamidino-2 phenylindole
Formamide
Fluorescence In Situ Hybridization
Jebel Ali Wastewater Treatment Plant
Quantitative Polymerase Chain Reaction
Volatile Fatty Acid

\section{REFERENCES}

1. Vanwonterghem, I., Jensen, P. D., Ho, D. P., Batstone, D. J. and Tyson, G. W., Linking Microbial Community Structure, Interactions and Function in Anaerobic Digesters using new Molecular Techniques, Current Opinion in Biotechnology, Vol. 27, pp 55-64, 2014, https://doi.org/10.1016/j.copbio.2013.11.004

2. Sundberg, C., Al-Soud, W. A., Larsson, M., Alm, E., Yekta, S. S., Svensson, B. H., Sørensen, S. J. and Karlsson, A., 454 Pyrosequencing analyses of Bacterial and Archaeal richness in 21 Full-scale Biogas Digesters, FEMS Microbiology Ecology, Vol. 85, No. 3, pp 612-626, 2013, https://doi.org/10.1111/1574-6941.12148 
3. Nelson, M. C., Morrison, M. and Yu, Z., A Meta-analysis of the Microbial diversity observed in Anaerobic Digesters, Bioresource Technology, Vol. 102, No. 4, pp 3730-3739, 2011, https://doi.org/10.1016/j.biortech.2010.11.119

4. Demirel, B. and Scherer, P., The Roles of Acetotrophic and Hydrogenotrophic Methanogens during Anaerobic conversion of Biomass to Methane: A Review, Reviews in Environmental Science and Biotechnology, Vol. 7, No. 2, pp 173-190, 2008, https://doi.org/10.1007/s11157-008-9131-1

5. Bitton, G., Wastewater Microbiology ( $3^{\text {rd }}$ ed.), Wiley-Liss, New York, USA, 2005, https://doi.org/10.1002/0471717967

6. Sträuber, H., Schröder, M. and Kleinsteuber, S., Metabolic and Microbial Community Dynamics during the Hydrolytic and Acidogenic fermentation in a Leach-bed Process, Energy, Sustainability and Society, Vol. 2, No. 13, 2012, https://doi.org/10.1186/2192-0567-2-13

7. Liu, C., Li, H., Zhang, Y., Si, D. and Chen, Q., Evolution of Microbial Community along with increasing solid concentration during High-solids Anaerobic digestion of Sewage Sludge, Bioresource Technology, Vol. 216, pp 87-94, 2016, https://doi.org/10.1016/j.biortech.2016.05.048

8. Dong, X., Xin, Y., Jian, W., Liu, X. and Ling, D., Bifidobacteriumthermacidophilum sp. nov., isolated from an anaerobic Digester, International Journal of Systematic and Evolutionary Microbiology, Vol. 50, Part 1, pp 119-125, 2000, https://doi.org/10.1099/00207713-50-1-119

9. Yamada, T., Anaerolineathermolimosa sp. nov., Levilineasaccharolytica gen. nov., sp. nov. and Leptolineatardivitalis gen. nov., sp. nov., Novel filamentous Anaerobes, and description of the new Classes Anaerolineae classis nov. and Caldilineae classis nov.in the Bacterial phylum Chloroflexi, International Journal of Systematic and Evolutionary Microbiology, Vol. 56, pp 1331-1340, 2006, https://doi.org/10.1099/ijs.0.64169-0

10. Schink, B., Energetics of syntrophic cooperation in methanogenic degradation, Microbiology and Molecular Biology Reviews, Vol. 61, No. 2, pp 262-280, 1997.

11. Koo, T., Shin, S. G., Lee, J., Han, G., Kim, W., Cho, K. and Hwang, S., Identifying Methanogen Community Structures and their correlations with performance Parameters in four Full-scale anaerobic Sludge digesters, Bioresource Technology, Vol. 228, pp 368-373, 2017, https://doi.org/10.1016/j.biortech.2016.12.118

12. Gerardi, M., The Microbiology of anaerobic Digesters ( $1^{\text {st }}$ ed.), Wiley-Interscience, Hoboken, New Jersey, USA, 2003, https://doi.org/10.1002/0471468967

13. Ziemiński, K. and Frąc, M., Methane fermentation Process as anaerobic digestion of Biomass: Transformations, Stages and Microorganisms, African Journal of Biotechnology, Vol. 11, No. 18, pp 4127-4139, 2012, https://doi.org/10.5897/AJBX11.054

14. Tatton, M., Archer, D., Powell, G. and Parker, M., Methanogenesis from Ethanol by defined mixed continuous Cultures, Applied and Environmental Microbiology, Vol. 55, No. 2, pp 440-445, 1989.

15. Sanz, J. and Köchling, T., Molecular Biology Techniques used in Wastewater treatment: An overview, Process Biochemistry, Vol. 42, No. 2, pp 119-133, 2007, https://doi.org/10.1016/j.procbio.2006.10.003

16. Yu, Y., Lee, C., Kim, J. and Hwang, S., Group-specific Primer and Probe sets to detect Methanogenic Communities using quantitative real-time Polymerase Chain reaction, Biotechnology and Bioengineering, Vol. 89, No. 6, pp 670-679, 2005, https://doi.org/10.1002/bit.20347

17. Amann, R., Krumholz, L. and Stahl, D., Fluorescent-oligonucleotide probing of whole Cells for determinative, phylogenetic, and environmental Studies in Microbiology, Journal of Bacteriology, Vol. 172, No. 2, pp 762-770, 1990, https://doi.org/10.1128/jb.172.2.762-770.1990 
18. Meier, H., Amann, R., Ludwig, W. and Schleifer, K., Specific Oligonucleotide Probes for in situ detection of a Major Group of Gram-positive Bacteria with low DNA G+C Content, Systematic and Applied Microbiology, Vol. 22, No. 2, pp 186-196, 1999, https://doi.org/10.1016/S0723-2020(99)80065-4

19. Manz, W., Amann, R., Ludwig, W., Wagner, M. and Schleifer, K., Phylogenetic Oligodeoxynucleotide Probes for the Major Subclasses of Proteobacteria: Problems and Solutions, Systematic and Applied Microbiology, Vol. 15, No. 4, pp 593-600, 1992, https://doi.org/10.1016/S0723-2020(11)80121-9

20. Bond, P. and Banfield, J., Design and performance of rRNA targeted Oligonucleotide Probes for in situ detection and Phylogenetic identification of Microorganisms inhabiting Acid Mine drainage Environments, Microbial Ecology, Vol. 41, No. 2, pp 149-161, 2001.

21. Roller, C., Wagner, M., Amann, R., Ludwig, W. and Schleifer, K., In situ probing of Gram-positive Bacteria with high DNA G+C Content using 23S rRNA-targeted Oligonucleotides, Microbiology, Vol. 140, Part 10, pp 2849-2858, 1994, https://doi.org/10.1099/00221287-140-10-2849

22. Devereux, R., Kane, M., Winfrey, J. and Stahl, D., Genus- and Group-Specific hybridization Probes for determinative and environmental Studies of Sulfate-Reducing Bacteria, Systematic and Applied Microbiology, Vol. 15, No. 4, pp 601-609, 1992, https://doi.org/10.1016/S0723-2020(11)80122-0

23. Manz, W., Amann, R., Vancanneyt, M., Schleifer, K. and Ludwig, W., Application of a Suite of $16 \mathrm{~S}$ rRNA-specific Oligonucleotide Probes designed to investigate Bacteria of the Phylum Cytophaga-flavobacter-bacteroides in the natural Environment, Microbiology, Vol. 142, Part 5, pp 1097-1106, 1996, https://doi.org/10.1099/13500872-142-5-1097

24. Egli, K., Bosshard, F., Werlen, C., Lais, P., Siegrist, H., Zehnder, A. and van der Meer, J., Microbial composition and structure of a rotating Biological Contactor Biofilm treating Ammonium-Rich Wastewater without Organic Carbon, Microbial Ecology, Vol. 45, No. 4, pp 419-432, 2003, https://doi.org/10.1007/s00248-002-2037-5

25. Raskin, L., Zheng, D., Griffin, M. E., Stroot, P. G. and Misra, P., Characterization of Microbial Communities in anaerobic Bioreactors using Molecular Probes, Antonie van Leeuwenhoek, Vol. 68, No. 4, pp 297-308, 1995, https://doi.org/10.1007/BF00874140

26. Griffin, M., McMahon, K., Mackie, R. and Raskin, L., Methanogenic Population dynamics during Start-up of anaerobic Digesters treating Municipal Solid Waste and Biosolids, Biotechnology and Bioengineering, Vol. 57, No. 3, pp 342-355, 1998, https://doi.org/10.1002/(SICI)1097-0290(19980205)57:3<342: :AID-BIT11>3.0.CO;2-I

27. Barlaz, M. A., Schaefer, D. M. and Ham, R. K., Bacterial Population development and Chemical Characteristics of refuse decomposition in a simulated Sanitary Landfill, Applied and Environmental Microbiology, Vol. 55, pp 55-65, 1989.

28. Widdel, F., Microbiology and Ecology of Sulfate- and Sulfur-reducing Bacteria, (Zehnder, A. J. B., ed.), pp 469-585, Biology of Anaerobic Microorganisms, John Wiley \& Sons, Inc., New York, USA, 1988.

29. Raskin, L., Rittmann, B. E. and Stahl, D. A., Competition and coexistence of Sulfate-reducing and Methanogenic Populations in anaerobic Biofilms, Applied and Environmental Microbiology, Vol. 62, No. 10, pp 3847-3857, 1996.

30. Widdel, F., Microbiology and Ecology of Sulfate- and Sulfur-reducing Bacteria, (Zehnder, A. J. B., ed.), pp 469-585, Biology of Anaerobic Microorganisms, John Wiley \& Sons, Inc., New York, USA, 1988.

31. Shu, D., He, Y., Yue, H. and Wang, Q., Microbial Structures and Community Functions of anaerobic Sludge in Six Full-scale Wastewater treatment Plants as 
revealed by 454 high-throughput pyrosequencing, Bioresource Technology, Vol. 186, pp 163-172, 2015, https://doi.org/10.1016/j.biortech.2015.03.072

32. Zhao, G., Ma, F., Wei, L. and Chua, H., Using Rice Straw fermentation Liquor to produce Bioflocculants during an anaerobic dry fermentation Process, Bioresource Technology, Vol. 113, pp 83-88, 2012, https://doi.org/10.1016/j.biortech.2011.11.040

33. Ariesyady, H., Ito, T. and Okabe, S., Functional Bacterial and archaeal Community Structures of major Trophic Groups in a Full-scale anaerobic Sludge Digester, Water Research, Vol. 41, No. 7, pp 1554-1568, 2007, https://doi.org/10.1016/j.watres.2006.12.036

34. Boone, D. and Bryant, M., Propionate-Degrading Bacterium, Syntrophobacterwolinii sp. nov. gen. nov., from Methanogenic Ecosystems, Applied and Environmental Microbiology, Vol. 40, No. 3, pp 626-632, 1980.

35. Seviour, R., Activated sludge- The G-bacteria, Encyclopedia of Environmental Microbiology (Bitton, G., ed.), pp 61-68, Wiley-Interscience, New York, USA, 2002.

36. Khan, M. and Faheem, S., Monitoring Bacterial diversity in a Full-scale Municipal Wastewater treatment Plant in Dubai by Fluorescence in situ hybridization Technique, International Journal of Environmental Research, Vol. 7, No. 2, pp 479-484, 2013.

37. Traversi, D., Villa, S., Lorenzi, E., Degan, R. and Gilli, G., Application of a Real-time qPCR Method to measure the Methanogen concentration during anaerobic digestion as an Indicator of Biogas production Capacity, Journal of Environmental Management, Vol. 111, pp 173-177, 2012, https://doi.org/10.1016/j.jenvman.2012.07.021

38. Amann, R. I., Ludwig, W. and Schleifer, K. H., Phylogenetic identification and in situ detection of individual Microbial Cells without cultivation, Microbiological Reviews, Vol. 59, No. 1, pp 143-169, 1995.

39. Garcia-Peña, E., Parameswaran, P., Kang, D., Canul-Chan, M. and Krajmalnik-Brown, R., Anaerobic digestion and co-digestion Processes of Vegetable and Fruit Residues: Process and Microbial Ecology, Bioresource Technology, Vol. 102, No. 20, pp 9447-9455, 2011, https://doi.org/10.1016/j.biortech.2011.07.068

40. Stams, A., Metabolic Interactions between anaerobic Bacteria in Methanogenic Environments, Antonie van Leeuwenhoek, Vol. 66, No. 1-3, pp 271-294, 1994, https://doi.org/10.1007/BF00871644

41. Regueiro, L., Veiga, P., Figueroa, M., Alonso-Gutierrez, J., Stams, A., Lema, J. and Carballa, M., Relationship between Microbial activity and Microbial Community Structure in Six Full-scale anaerobic Digesters, Microbiological Research, Vol. 167, pp 581-589, 2012, https://doi.org/10.1016/j.micres.2012.06.002

42. Yang, Y., Yu, K., Xia, Y., Lau, F., Tang, D., Fung, W., Fang, H. and Zhang, T., Metagenomic analysis of Sludge from Full-scale anaerobic Digesters operated in Municipal Wastewater Treatment Plants, Applied Microbiology and Biotechnology, Vol. 98, pp 5709-5718, 2014, https://doi.org/10.1007/s00253-014-5648-0

Paper submitted: 03.09.2017

Paper revised: 20.05 .2018

Paper accepted: 28.05.2018 